\title{
Time series livestock diet optimization: cost-effective broiler feed substitution using the commodity price spread approach
}

\author{
Othman Alqaisi ${ }^{1 *}$, Oghaiki Asaah Ndambi ${ }^{2}$ and Ryan Blake Williams ${ }^{3}$
}

* Correspondence:

othman.alqaisi@gmail.com

'Department of Animal and Veterinary Sciencs, College of Agricultural and Marine Sciences, Sultan Qaboos University, P.O. Box 34, 123 Al khoudh, Sultanate of Oman

Full list of author information is available at the end of the article

\begin{abstract}
Sustainable feed formulation (defined here as nutritional and economic feed optimization) is substantial in feed chain production from crop farmers to livestock producers. Diet formulation employing a static linear programming (LP) approach, which is widely used in trading firms and feed production facilities, does not allow for intertemporal flexibility. Our approach allows the interaction between feed components over time, considering the volatile global feed prices, thereby improving sustainability in feed formulation and feed availability. The objectives of this study were to (1) develop a multi-stage LP feed model, (2) demonstrate its potential use in broiler feeding, and (3) illustrate the impact of feed input price spread (variation) on the composition of broiler diets. Modeling resulted in reciprocal relationships between conventional feeds and byproducts at different rates. Based on the price spreads expressed as a percentage of DDGS (distiller's dried grains with solubles) price compared to corn price, three positions of dietary switch were identified; corn-DDGS price spreads of higher than 94\%, between 76 and 94\%, and lower than 76\% corresponding to limited/no inclusion, partial inclusion, and maximum replacement of corn by DDGS, respectively. Rapeseed meal inclusion was 4, 5, and 6\% in the corn-based starter, grower, and finisher diets, respectively, and its potential to replace soybean meal was limited by its higher fiber content. Based on the simulated compound feed prices, the global broiler feed industry could gain 1.7 billion USD through improved resources planning.
\end{abstract}

Keywords: Multi-stage linear-programming, Broiler diet, Feed industry, Trading, Price spread, Byproducts

\section{Background}

The global compound feed industry production is estimated at 996 million metric tons and is valued at 450 billion USD in 2015. The poultry compound feed industry itself accounts for 463 million metric tons or $47 \%$ of the global industrial feed production (Alltech 2016). In the last 10 years, feed prices have been very volatile, with a peak in 2008 (FAO 2011), mostly linked to increasing demand from developing countries and competition with renewable energy production from biofuels (Godfray et al. 2010). Feed costs account for up to $70 \%$ of total costs in typical livestock production systems (i.e., intensive dairy farming, (Alqaisi et al. 2011) and up to 69\% in intensive poultry production systems (Donohue and Cunningham 2009). Studies show that the

(C) The Author(s). 2018 Open Access This article is distributed under the terms of the Creative Commons Attribution 4.0 International License (http://creativecommons.org/licenses/by/4.0/), which permits unrestricted use, distribution, and reproduction in any medium, provided you give appropriate credit to the original author(s) and the source, provide a link to the Creative Commons license, and indicate if changes were made. 
replacement of some feed ingredients with agro-industrial byproducts would lead to a reduction in feed costs and lower greenhouse gas emissions per unit of output (Alqaisi et al. 2014). However, the rate of inclusion of these byproducts should also depend on their market prices and the price difference between the conventional feeds and the byproducts. Whatever the inclusion rates of various feed ingredients in the poultry diet, a lower cost diet will significantly reduce the cost of poultry production and/or more profitability of feed producers.

Diet optimization is another effective means of cutting costs in the poultry feed industry, and linear programming models have been widely used for this purpose. These models have traditionally focused on maximizing producer profits in the short run, but such models do not provide producers with information about how to optimally substitute between feed ingredients as their relative prices change. Makkar and Ankers (2014) suggested that the focus needs to shift from profit maximization toward feed and other input use optimization. The most common application of linear programming (LP) models in solving the diet problem has been to formulate diets using a static approach and for a short term (i.e., per ration formulation or per animal life cycle in other cases).

These models have been commonly used for over a century and in a similarly restrictive fashion, taking information on the target animal species and its requirements, feed ingredients, and market feed prices as given. These parameters are used in the LP model to minimize the feed cost, considering nutritional limitations (Peric and Babic 2009, Saxena 2011; Žgajnar et al. 2010). The biggest challenges in LP modeling in the 1980s were the absence of information about the biological restrictions of animals and the varying quality of feed ingredients (Saxena and Chandra 2011; Beckman et al. 2011). This has greatly improved over the years as LP modeling has increasingly considered aspects such as the physiological stage of animals (Saxena and Chandra 2011; Singh and Saxena 2015). The current LP models in the feed industry, as well as at the farm level, do not allow the user to simulate time series scenarios, which could capture the fluctuating market prices for feed inputs. Therefore, the validity of their solutions is weakened by daily, weekly, and monthly variations in feed prices. Hence, this creates economic pressure on decision-makers and firms, which rely on these results for strategic planning, since the model outcomes become irrelevant shortly after they are derived.

In the feed industry, there is a common classification of feeds into energy-rich and protein-rich feeds, whereby feed ingredients within each group could be substituted for each other at different percentages without necessarily affecting the animals being fed. Therefore, in a fluctuating price situation, a multi-stage LP offers the advantage of determining the price spread-for instance, between corn and wheat or between distiller's dried grains with solubles (DDGS) and corn at which it is important to replace part or all of one feed ingredient with the other. Previous works utilizing multi-period LP models have tended to focus on issues such as the variation in feed supply, the quality of feedstuffs, and animal requirements to optimize diets to achieve productivity goals (Reynoso-Campos et al. 2004; Nicholson et al. 1994). However, the issue of commodity price spread and dietary dynamics over time, and its relationship with dietary feeds and substitution rates, has not been adequately evaluated. 
In many applications of linear programming to a real trading or feed production situation, time is not taken as a specific variable factor. Furthermore, the multi-stage LP approach provides time series estimates on the "price limits," which are important in examining the stability of the diet over a period of time. This approach, which adds an extra time series dimension to the diet problem, allows the interaction between feed components over time. It also allows the possibility of using agro-industrial byproducts, which are only available and/or are very cheap during particular seasons of the year, as animal feeds. The multi-stage LP modeling approach is useful in providing answers for decision-makers concerning the price spread between commodities and the rates at which commodities could replace one another under volatile price situations. Furthermore, typical static LP models may provide per time price spreads between feeds, but they do not provide comprehensive information on the feed substitution rates related to changes in price spreads.

Defined in this way, the problem requires developing a general multi-stage LP model for optimization of a feeding diet. Consequently, the objectives of this study are:

To develop the multi-stage LP model that produces time series least cost results for different livestock species,

To apply a multi-stage LP method in solving two modeled examples of broiler feed formulation,

Present and analyze programming results and extract conclusions from the developed method.

\section{Methods}

\section{Feed production process}

Compound feed production and commodity trading are a continuous process based on daily, weekly, and monthly activities. Monthly commodity prices in feed trading and production are used in the current analysis due to the availability of the data.

The supply chain of feed materials, which begins with producers and ends with consumers, is illustrated in Fig. 1. Within the chain, farmers produce grains and oil crops and sell them either directly to trading companies in the case of feed grains or to crushing plants in the case of oil-rich seeds such as soybeans and sunflower seeds. Thereafter, the meals are purchased by trading companies. Alternatively, trading

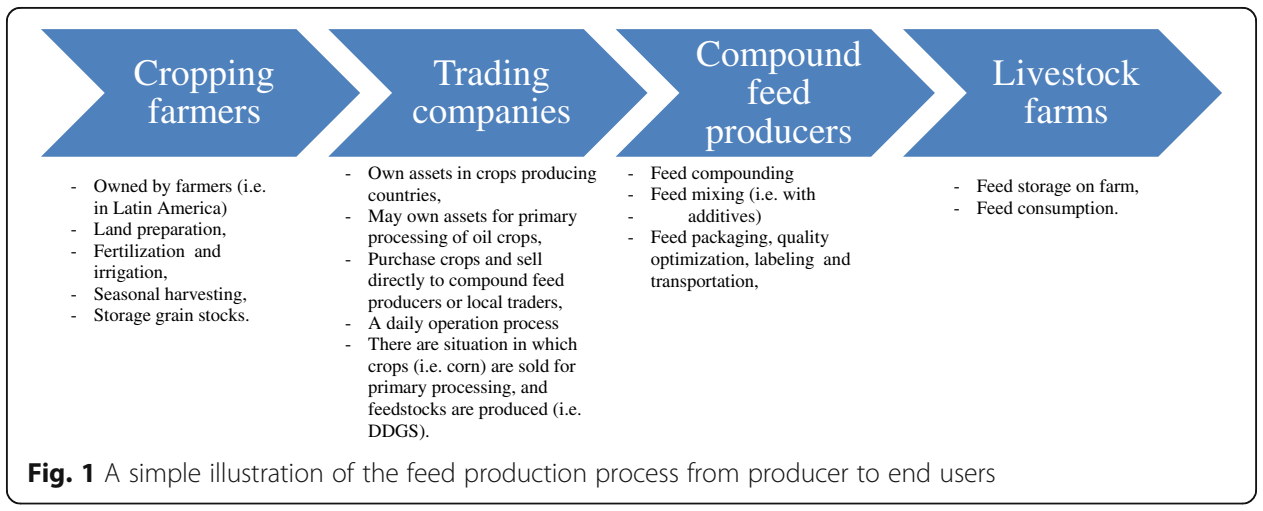


companies may own crushing plants and trade in feed meals. In the second part of the chain, trading companies sell grains and meals to feed producers. The current analysis is designed to mimic a production process in a feed mill acquiring feed materials from a trading company. The method under investigation is that of monthly analysis of a multi-stage linear programming model (multi-stage LP) output.

\section{Multi-stage LP model}

The objective of the multi-stage linear programming model is to produce a feed blend at minimum cost in different periods (defined here as a month). The model selects the optimal proportion of feed ingredients to produce a least cost diet given feed nutritional composition, animal nutritional requirements, and feed prices.

The problem of determining the commodity of interest in the produced feed blend emerges when the price gap between two protein or energy sources is small. This situation arises regularly because feed prices are volatile. The challenge is exacerbated when designing a commodity trade without knowing the optimal price spread between two commodities, which is a well-known problem for feed commodities trading companies. Consequently, this study examines the price commodity spread in comparison with the commodity trading alternative (i.e., corn versus wheat).

To determine the time (defined by the month) when a diet adjustment is required, and the proportion of an alternative feed commodity to be included to the new diet, a multi-stage LP model was developed for broiler chicken feeding in two modeled cases. The multi-stage LP model in this study is a quick and time efficient approach to optimize diets. Unlike static LP models, this multi-stage LP model minimizes a sequence of decision variables and provides time series relationships between decision variables and constraints via simulated solutions. The resulting relationships are estimated using the open source $R$ programming software ( $R$ Core Team 2016). The model is based on mixed integer linear programming packages. It provides pure linear, integer or binary, semi-continuous, and special-order set models based on the simplex algorithm method. The model provides-but is not limited to-a sequence of multistage results by retrieving values from a sequence of successfully solved single-period LP models. The results produced by this model allow the decision-maker to investigate the relationships between objective function values, values of the decision variables, values of the constraints, dual variables (the reduced costs), and the sensitivity of the objective function. In many respects, the model serves to provide an efficient sensitivity analysis of optimal feed mixes under alternative input prices and animal nutritional requirements.

\section{Model structure}

The general structure of the multi-stage LP is described as follows:

$$
\begin{gathered}
\min _{x} \mathrm{TC}=\sum_{t}^{T} \sum_{i}^{n} c_{\mathrm{it}} x_{\mathrm{it}} \\
\text { subject to } \\
\sum_{i}^{n} a_{\mathrm{ij}} x_{\mathrm{i}} \gtreqless b_{\mathrm{j}} \forall j \in J \\
X_{\mathrm{it}} \geq 0 .
\end{gathered}
$$


where TC is the total cost of the feed ration, $t$ is the time period (month), $c_{\mathrm{i}}$ is the per unit cost of feed ingredient $i$, and $x_{\mathrm{i}}$ is the quantity of feed ingredient $i$ in the feed ration. $J$ is the set of nutrients that must be considered in the feed ration, with $j$ being one of the nutrients of the set of $J, a_{\mathrm{ij}}$ is the quantity of nutrient $j$ in feed ingredient $i$, and $b_{\mathrm{j}}$ is the required amount of each nutrient $j$ in the feed ration. The sign of the relationship for each of the nutrients depends on the particular nutrient and the nutrient balance that must exist in the ration.

Monthly commodity feed prices were collected from the World Bank (2016) and the USDA (2016). The general structure of the model for a single month is shown in Tables 1 and 2. Each table is divided into two parts. The upper part of the table includes multi-period price data for the objective function, namely, the monthly feed commodity prices. The monthly feed commodity prices are saved in external text format file and linked to the LP model in the R console with the apply function to repeat optimization for each individual monthly set of prices, subject to the model parameters. The lower part of the table consists of information relevant to the feed composition and the model right-hand side constraints and boundaries.

Three main factors were considered for the diet optimization simulation: the decision variables (feed composition), the objective function (feed prices), and the model constraints (feed requirements). The nutritional requirements for broiler chicken and the feed composition were taken from the NRC (1994) and Leeson and Summers (2005).

The non-zero and non-negative constraints were considered in both equality and non-equality forms. The minimization of the objective function in each period is subject to a set of constraints. These are the feed requirement variables which are composed of the weight of total formulated diet in kilogram or percentage, metabolizable energy (ME) in kilocalorie, and the dietary percentages of crude protein $(\mathrm{CP})$, calcium, phosphorus, arginine, fiber, lysine, and methionine and cysteine (Meth. Cyst.). Furthermore, no upper or lower bounds were set in the model for the feed inclusion rate. Ultimately, the optimized feed results are given in percentages.

\section{Modeled examples}

Taking, as a basis, the model structure described herein, two simulation models were defined which could represent a potential long-term feed production strategy in an enterprise and in a region. To our knowledge, the capabilities of such a multi-stage LP model in long-term trade and animal feed production have not previously been evaluated for its efficacy in a particular industry. We aim to evaluate the historical monthly optimal dietary feed composition in two different broiler feeding problems. Two cases were modeled with three formulation strategies in each model which simulate the life cycle of a commercial broiler chicken. This included a starter phase of 0 to 18 days, grower phase between 19 and 30 days, and finisher stage between 31 and 41 days. The formulated diets are considered to be nutritionally satisfactory to produce chickens with a final body weight of about $2.5 \mathrm{~kg} / \mathrm{bird}$ at age 41 days with ending feed conversion of $1.7 \mathrm{~kg}$ feed/kg gain (Leeson and Summers 2005).

For feed producers, this is justified by the short life cycle of broiler production on farm. However, for trading companies which provide commodities to feed producers, 


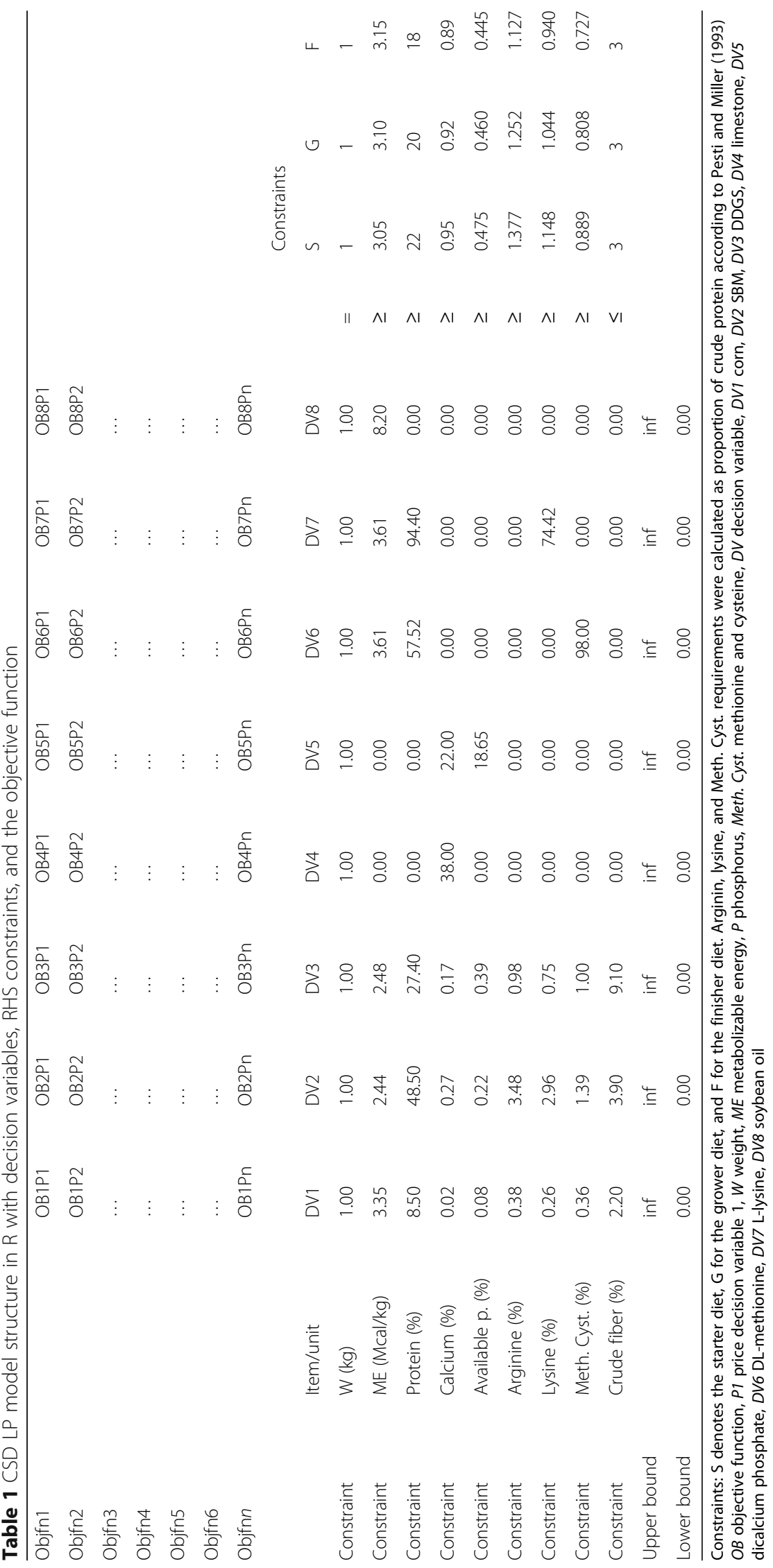




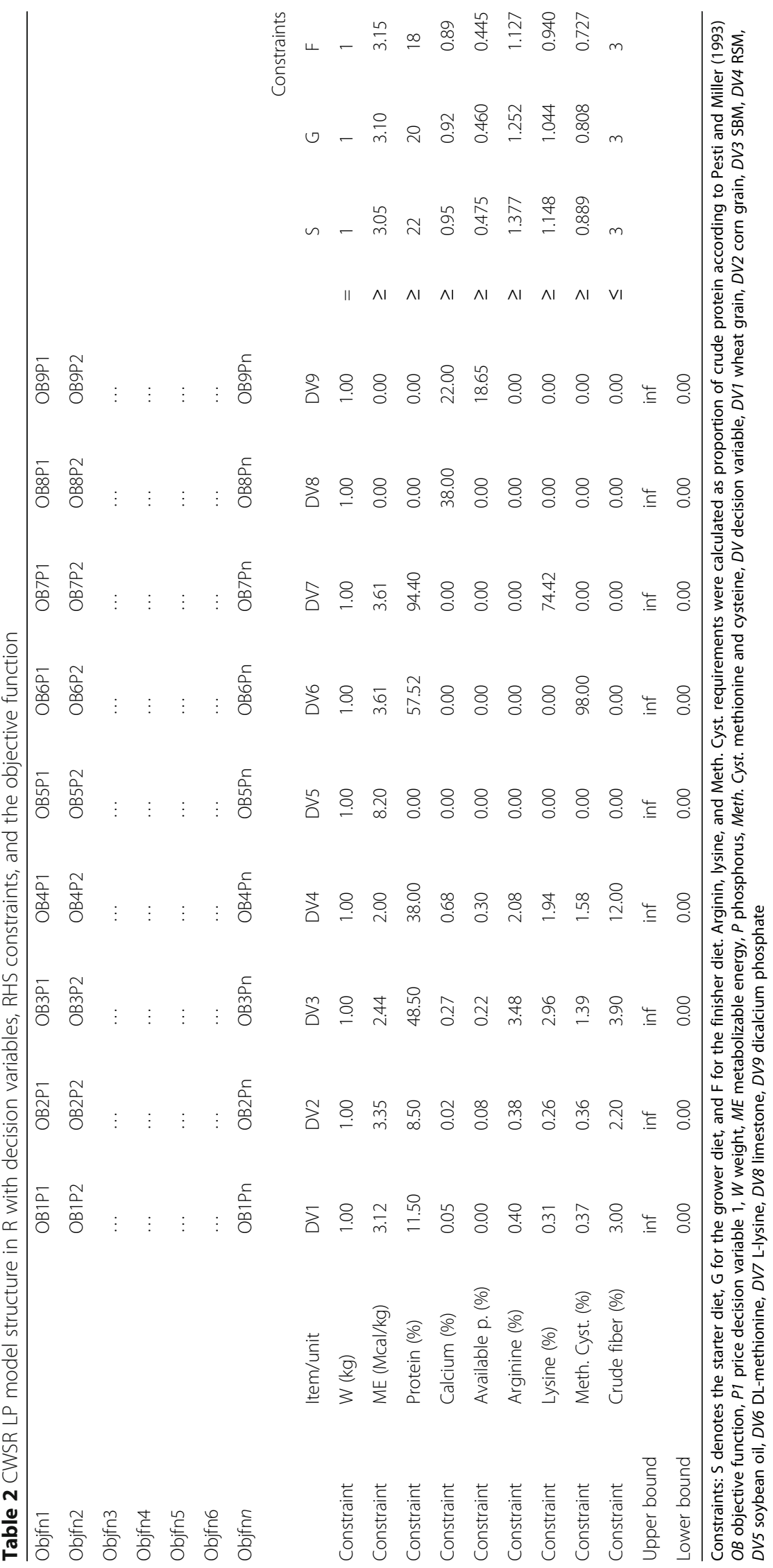


assuming the availability of resources and the activities undertaken (i.e., purchasing and selling commodities from producing to importing countries) using the static approach may not be efficient, given that feed prices change daily. Therefore, the least cost formulation procedure needs to consider the time dimension and the potential for change in the preference of one input over another.

Feed commodities of corn, DDGS, and soybean meal (SBM) were used in the "CSD" model. Monthly market feed prices were available between 2009 and 2016. Furthermore, feed additives of methionine and cysteine (Meth. Cyst.), lysine, dicalcium phosphate (DCP), limestone, and soy oil were included in the modeled diets to mimic feed formulation and production processes. The "CWSR" model was designed with feed commodities of corn, wheat, rapeseed meal (RSM), and SBM in the diet simulation, in addition to the feed additives as described in the CSD model. Monthly market feed prices were available between 2004 and 2016.These commodities are globally available and extensively used and are satisfactory to formulate nutritional broiler diets. The reasons for suggesting these two particular models are that (i) DDGS is a commonly used byproduct in US broiler feed production (Hoffmann et al. 2011) and used to substitute for corn and SBM, and (ii) corn and wheat are used in EU broiler feed production as energy sources, and SBM and RSM are used as protein sources (de Visser et al. 2014). In each of these cases, it is not clear at which price and inclusion rate one commodity would be substituted for the other.

\section{Results and discussions}

The multi-stage LP model was implemented in R software version 0.99.892.0. The solution time varied depending on the instance being solved but was within the range of 0.5 and 1 second. The solutions of the LP model for each of the solved problems are given by the optimal inclusion rate in percentage that minimizes the total formulated feed cost.

\section{CSD model}

Figures 2 and 3 provide a graphical representation of the simulated inclusion rates of DDGS, corn, and SBM in different broiler life cycle diets. The simulated feed formulation shows a reciprocal relation between DDGS and both corn and SBM dietary inclusion rates. The simulated inclusion rate of feeds was stable between late 2008 and 2011, except for one period in which SBM and corn replaced DDGS. The figure further illustrates that from late 2011 onward, the optimal solution would require an increased incidence of substitution between inputs.

Maximum corn inclusion rates were 58,65 , and $70 \%$ for the starter, grower, and finisher diets, respectively. In the starter diet, the DDGS inclusion rate varied between 4.3 and 5.5\%. The inclusion rate of DDGS was higher in the grower diet and varied between 1.2 and 6.8\% (Table 3). The highest DDGS inclusion rate was observed in the finisher diet at $8 \%$. DDGS was a substitute for both corn and SBM at different rates. This result is due to the high protein and energy content of DDGS. However, the maximum inclusion rate indicates that crude fiber in this byproduct is a limiting factor for further inclusion, regardless of its price. The increase in DDGS inclusion rate-from starter to grower and finisher diets-is driven by the changes in energy, protein, and 


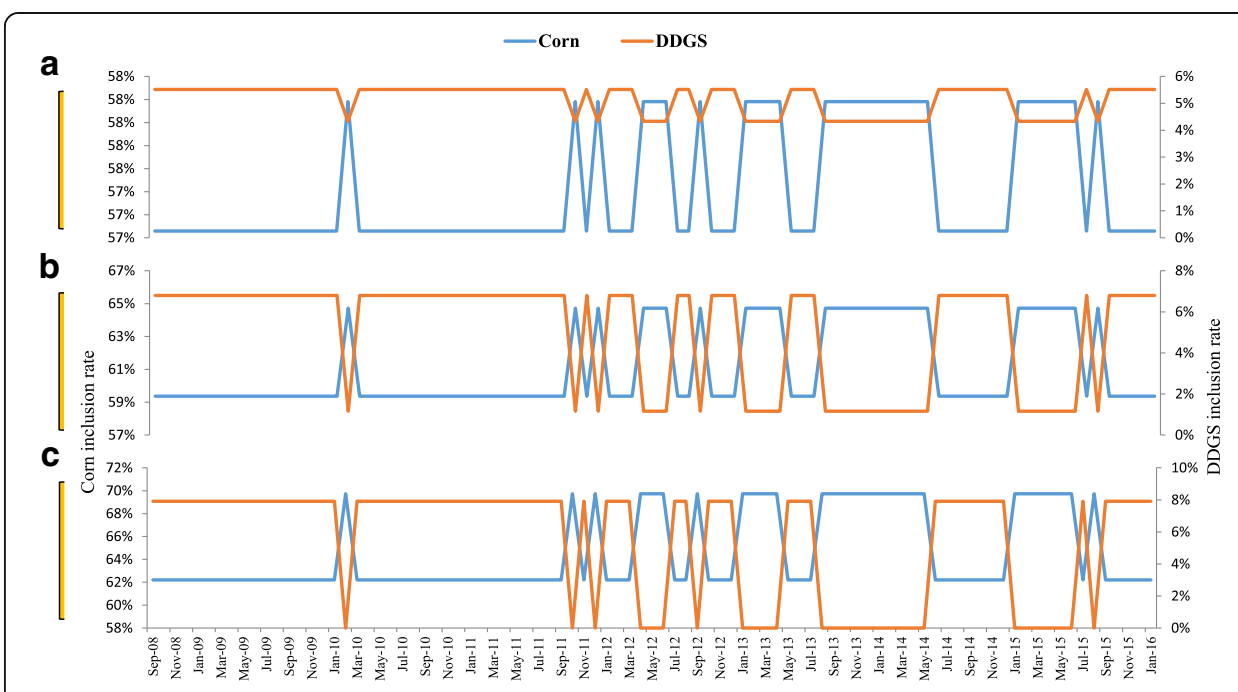

Fig. 2 Simulated optimal inclusion rates of corn and DDGS based on nutritional requirements and monthly feed prices from 2008 to 2016. a Starter, b Grower, and c Finisher broiler diets

lysine requirements in the formulated diets. This result corresponds with those of the study by Loar (2012) and Walugembe et al. (2014) who formulated 8\% dietary DDGS in broiler diets, in which their diets substituted both corn and SBM. Since DDGS quality varies greatly in the literature, the simulated DDGS inclusion rate suggested in our study may differ depending on the composition of the byproduct and the fiber constraints employed here. Furthermore, the results obtained herein may be different if additional feed sources had been used in the model. Therefore, the DDGS inclusion rates suggested by the current study are particular to the model parameters used here within.

The magnitude with which DDGS replaces corn is significantly higher than it is for replacing SBM, indicating its importance as an energy feed source. For instance, in the starter diet, an increase in DDGS inclusion from 4.3 to $5.5 \%$ replaced $1.1 \%$ corn and

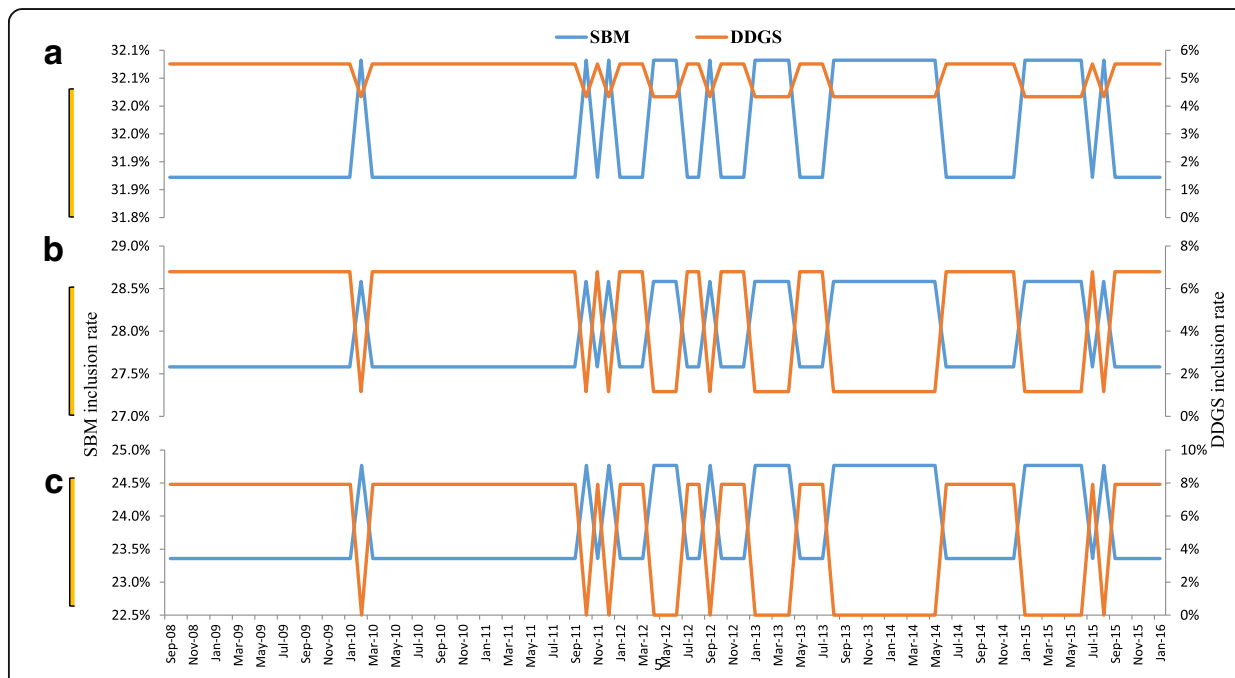

Fig. 3 Simulated optimal inclusion rates of soybean meal and DDGS based on nutritional requirements and monthly feed prices from 2008 to 2016. a Starter, b Grower, and c Finisher broiler diets 
Table 3 Minimum, maximum and mean percentage (\%) values of feed ingredients for the CSD multi stage LP model in starter, grower and finisher broiler diets

\begin{tabular}{ccccccccc}
\hline & Corn & SBM & DDGS & Soy oil & Meth & Lys & Lime & DCP \\
\hline Starter & & & & & & & & \\
Min & 57.1 & 31.9 & 4.3 & 2.5 & 0.2 & 0.022 & 0.9 & 1.8 \\
Max & 58.2 & 32.1 & 5.5 & 2.6 & 0.2 & 0.023 & 0.9 & 1.8 \\
Mean & 57.4 & 31.9 & 5.1 & 2.6 & 0.2 & 0.023 & 0.9 & 1.8 \\
Grower & & & & & & & & \\
Min & 59.4 & 27.6 & 1.2 & 2.4 & 0.1 & 0.028 & 1.2 & 1.7 \\
Max & 64.7 & 28.6 & 6.8 & 3.2 & 0.2 & 0.03 & 1.2 & 1.8 \\
Mean & 61 & 27.9 & 5 & 3 & 0.2 & 0.029 & 1.2 & 1.7 \\
Finisher & & & & & & & & \\
Min & 62.2 & 23.4 & 0 & 2.5 & 0.1 & 0.034 & 1.1 & 1.6 \\
Max & 69.7 & 24.8 & 7.9 & 3.6 & 0.1 & 0.036 & 1.2 & 1.7 \\
Mean & 64.6 & 23.8 & 5.4 & 3.2 & 0.1 & 0.036 & 1.2 & 1.6 \\
\hline
\end{tabular}

only $0.2 \%$ SBM. The substitution of both corn and SBM by DDGS further affected soy oil and lysine inclusion rates, which increased by $0.2 \%$ and by $0.0004 \%$, respectively.

The inclusion rate of DDGS in both grower and finisher diets was more evident. In the simulated grower diets, the increase in DDGS inclusion rate between months at $5.6 \%$ was used to substitute $5.4 \%$ corn and $1 \%$ SBM. However, soy oil was increased by $0.8 \%$, and lysine inclusion was increased at $0.002 \%$. Similarly, in the simulated finisher diet, an increase in DDGS inclusion rate of $8 \%$ combined with $1.1 \%$ soy oil and $0.0025 \%$ lysine was used to substitute $7.5 \%$ corn and $1.4 \%$ SBM. Loar et al. (2012) suggested an upper inclusion limit of DDGS in finisher diets of $14 \%$. The difference found in the current study could be due to the differences in feeds included in the diets, as well as the constraint of fiber set at $3 \%$ in the current study. However, a DDGS inclusion rate of about $14 \%$ was possible in our model when the total fiber limit was set at $4 \%$. Therefore, $1 \%$ of DDGS combined with $0.00032 \%$ lysine and $0.14 \%$ soy oil in broiler diets could replace $0.95 \%$ corn and $0.2 \%$ SBM. This means that, when using DDGS in the diet formulation, it should be considered that additional oil and lysine sources are required. This analysis demonstrates the viability of the proposed method to evaluate feed resources, particularly feed byproducts which are used to substitute typical feeds such as corn, wheat, and SBM.

Figure 4 shows the ranked percentage price spread expressed as the ratio between SBM and DDGS (i.e., DDGS/SBM), between DDGS and corn (i.e., DDGS/corn), and the corresponding DDGS inclusion rate. Ranked as such, this method is important to find the price spread which corresponds to the switch between feeds in the historical diet simulation. In the simulated starter and grower diets, DDGS substituted for corn and SBM at any SBM and corn price spread, but with a greater amount and frequency in the starter diet. However, in the simulated finisher diet, DDGS had a higher substitution rate in terms of quantity, but at a lower frequency of substitution over the study period compared to the starter and grower diets. Figure 4 clearly illustrates three distinct levels of price spread. A price spread of less than 76\% (i.e., DDGS $=76 \%$ of corn price), in which DDGS inclusion was at its maximum level, ; a price spread ranging between $76 \%$ 


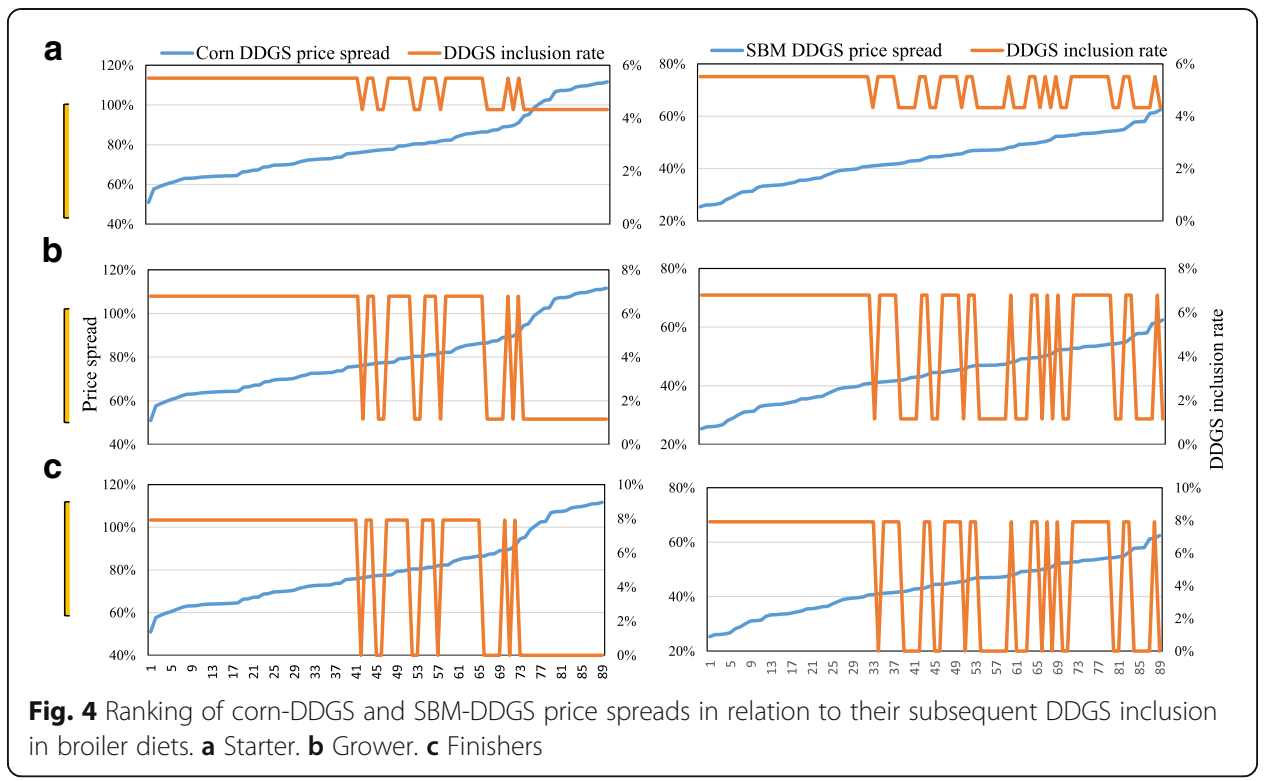

and 94\%, where DDGS was included in frequent periods depending on the broiler diet type; and a price spread greater than $94 \%$.

At a price spread greater than $94 \%$, DDGS remained in the diet at the lowest inclusion rate, as in the case of starter and grower diets, or it was not included at all as in the case of the finisher diet. The DDGS corn price spread seems to be highly correlated with the composition of the diet and animal requirements (i.e., nutritional requirement constraints of the LP model). This information is, therefore, important when conducting trades based on feed price spreads and when planning long-term dietary formulation. Clustering life cycles of animals, on one hand, and formulating diet per cluster, on the other hand, provides further information about the commodity price spread and successful optimization of trades.

Similarly, and because DDGS substitutes for both corn and SBM, it is important to examine the DDGS and SBM price spread. In the simulated starter and grower diets, DDGS remains a substitute for SBM in all formulated diets. At a price spread of less than $41 \%$, DDGS was included at the maximum inclusion rate. At a price spread greater than or equal to $41 \%$, DDGS remains in the diet at variable inclusion rates. Derived as such, the price spread determined in the current study provides valuable information that may be employed, along with fundamentally calculated price spreads, by feed trading companies.

Variations in the objective coefficients of the multi-stage LP model are presented in Additional file 1: Annex 6. The results show the upper and lower prices of the objective functions of corn, DDGS, and SBM in the CSD model. Due to the large data of extracted objective coefficients, we present one example from each model. The idea of presenting these results is to elaborate on which commodity price levels the formulated diets will remain stable (i.e., stability of the dietary composition results), represented by the area between curves. In other words, these prices represent the range of objective function price for a given feed input, at any given time period, for which the optimal mix of feed inputs would not change. The larger the range of prices, the less sensitive the model solution is to change in particular input. In the starter diet, the objective function prices for corn varied between a 
minimum limit of 59 and a maximum of 324 USD, and between - 937 and 280 USD for DDGS. The structure of the formulated diets is more sensitive to DDGS price as compared to SBM and corn prices.

\section{CWSR model}

Figure 5 provides a graphical representation of the historical simulation for corn and wheat inclusion rates in starter, grower, and finisher broiler diets in the CWSR model. In the starter diet, the maximum inclusion rate of wheat was $51 \%$, versus $60 \%$ for corn. The inclusion rate of both corn and wheat increased, with a maximum for corn of $62 \%$ and $65 \%$ in the grower diet, and 66 and 70\% in the finisher diets (Table 4). The minimum inclusion rate of corn versus wheat in the starter and grower diets indicates that corn could not be completely replaced by wheat. This could be due to the fiber and energy composition differences in both feeds, since wheat contains 36\% more fiber and 7\% less ME compared to corn. Therefore, formulating starter diets solely based on wheat did not provide the theoretical nutrient requirement considered in the current study.

The inclusion rate of SBM (Fig. 6) varied between 31 and 35\% in the starter diet, 26 and $30 \%$ in the grower diet, and between 22 and $25 \%$ in the finisher diet. RSM substituted SBM partially in all dietary types. The proportion of RSM inclusion increased progressively in the starter, grower, and finisher diets from 4 to $5 \%$ and $6 \%$, respectively. The simulated SBM inclusion rates over time varied depending on the corn and wheat inclusion rates. For instance, at 50\% wheat inclusion in the starter diet, SBM inclusion was 33\% and 0\% for RSM. However, at 59\% corn inclusion rate, SBM was included at $32 \%$ and RSM at $4 \%$. The analysis shows that in the corn-based diet, $1 \%$ of RSM could replace $0.7 \%$ SBM and $0.4 \%$ corn, in addition to reducing soy oil by $0.14 \%$ and Meth. Cyst. by $0.0046 \%$ (Fig. 7).

RSM is an important source for Meth. Cyst.; however, its inclusion rate is limited by its high fiber content. The literature indicates the use of RSM in broiler diets at

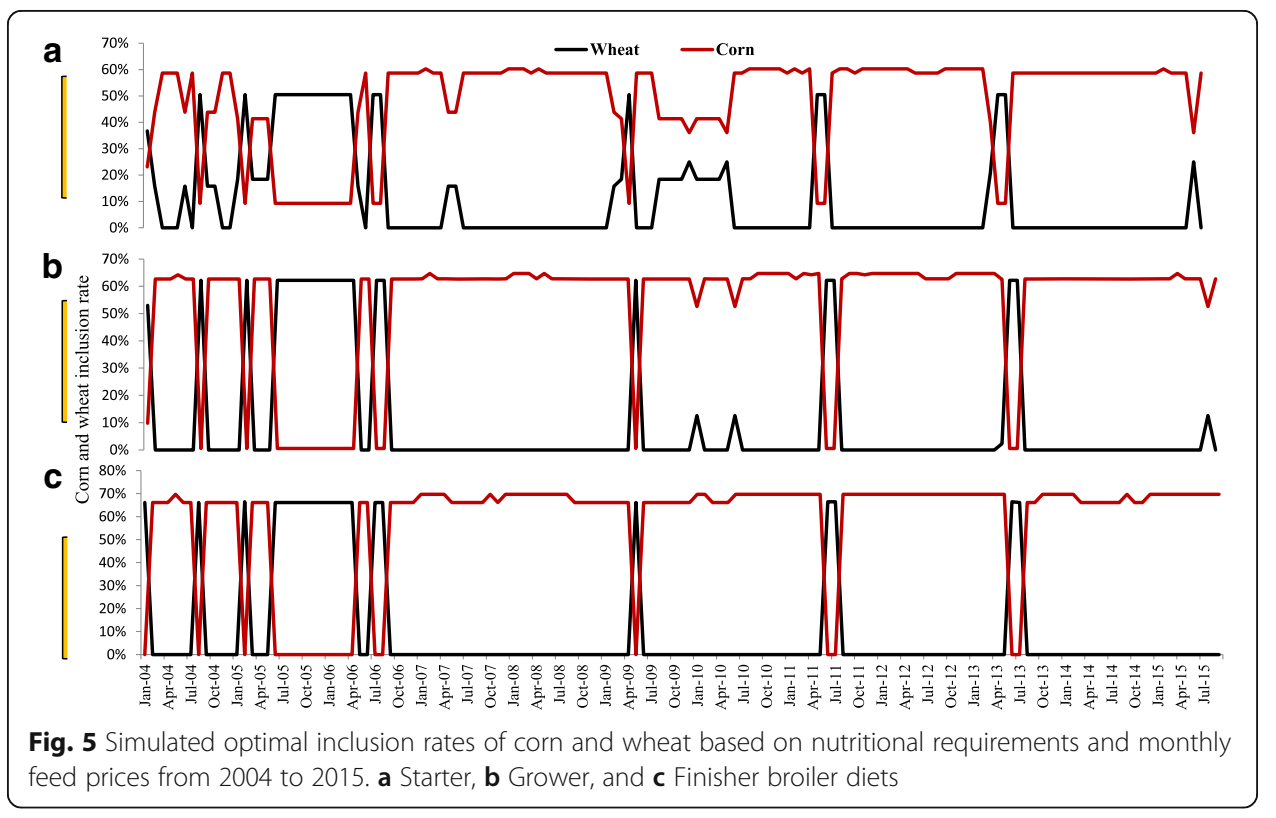


Table 4 Minimum, maximum, and mean percentage (\%) values of feed ingredients for the CWSR multi-stage LP model in starter, grower, and finisher broiler diets

\begin{tabular}{lllllllllll}
\hline & & Wheat & Corn & SBM & RSM & Soy oil & Meth & Lys & Lime & DCP \\
\hline Starter & Min & 0 & 9.3 & 31.5 & 0 & 2.2 & 0.2 & 0 & 0.7 & 1.9 \\
& Max & 50.5 & 60.3 & 34.6 & 3.9 & 4.3 & 0.2 & 0.009 & 0.9 & 2.1 \\
& Mean & 10.7 & 48.7 & 32.5 & 2.3 & 2.9 & 0.2 & 0.001 & 0.8 & 1.9 \\
\multirow{5}{*}{ Grower } & Min & 0 & 0.5 & 26.1 & 0 & 2.4 & 0.1 & 0 & 0.9 & 1.8 \\
& Max & 62.2 & 64.7 & 29.7 & 5 & 5.3 & 0.2 & 0.022 & 1.1 & 2.1 \\
& Mean & 9.5 & 53.7 & 27.4 & 3 & 3.3 & 0.2 & 0.009 & 1.1 & 1.9 \\
\multirow{5}{*}{ Finisher } & Min & 0 & 0 & 21.7 & 0 & 2.5 & 0.1 & 0 & 0.9 & 1.8 \\
& Max & 66.4 & 69.7 & 24.8 & 5.8 & 5.8 & 0.1 & 0.034 & 1.1 & 2.1 \\
& Mean & 9.9 & 58 & 23.6 & 2.3 & 3.4 & 0.1 & 0.023 & 1 & 1.8 \\
\hline
\end{tabular}

different inclusion rates, and our results corresponded with some of these (Thacker and Petri 2011), but do not agree with others (Gopinger et al. 2014) who formulated RSM diets with crude fiber ranging between 4.4 and $6.7 \%$. This is likely due to differences in the formulation of the objective and the constraints used (i.e., maximum fiber requirements) in the current study versus other studies. Furthermore, there were differences in the RSM composition and its prices used here compared with alternative studies. Concerning the fiber contents of RSM, we modeled the dietary simulation based upon a maximum $3 \%$ fiber content. When the maximum fiber content was changed to $4 \%$, the RSM inclusion rate in the starter diet ranged between 6 and 15.6\%. Therefore, the fiber limit used in diet formulation is responsible for most of the variation in RSM inclusion rates found in previous studies. Importantly, the model under consideration is flexible to adjust the nutritional characteristics of the feed to desired requirements.

The results of this study clearly indicate that in wheat-based diets (i.e., inclusion rate $>50 \%$ ), the inclusion of RSM in the starter diet will not be economically viable. However, the greater the wheat content of the diet, the more the need for soy oil as an

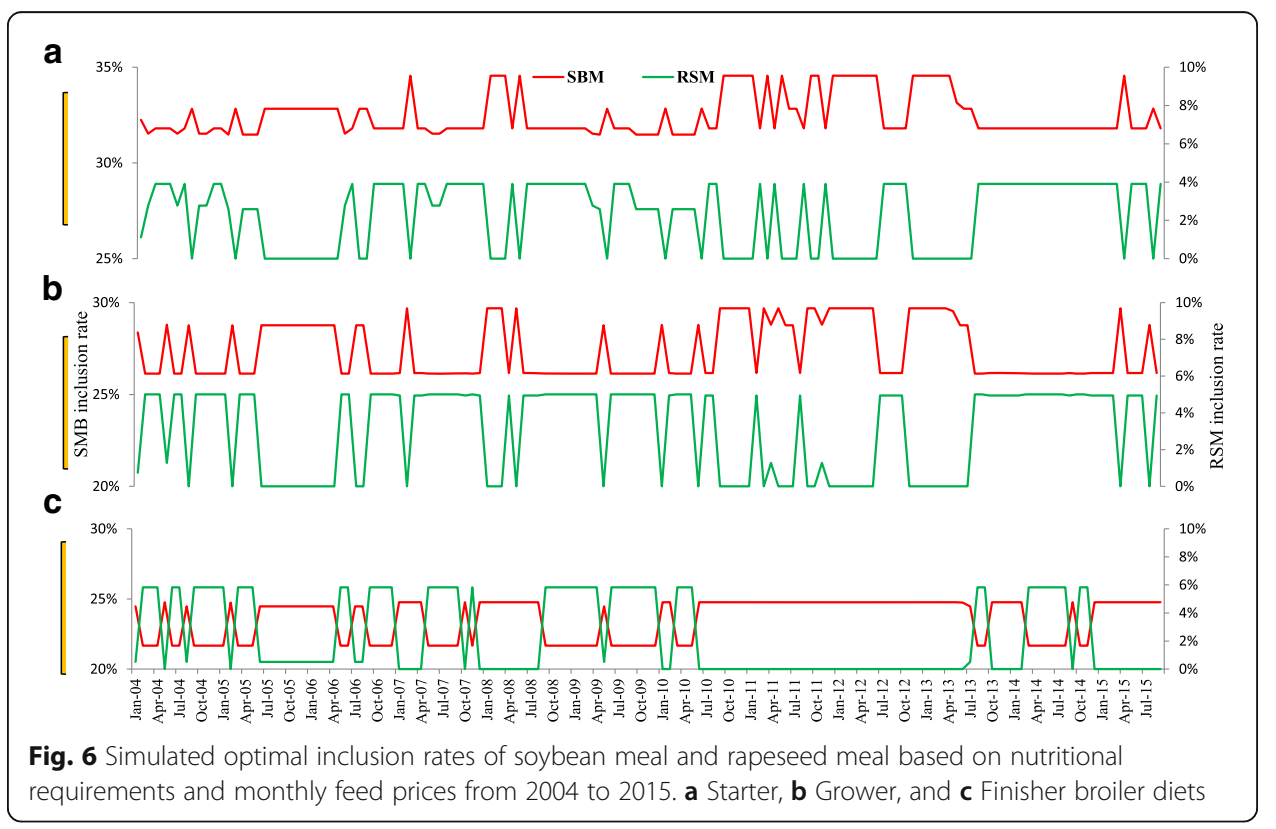




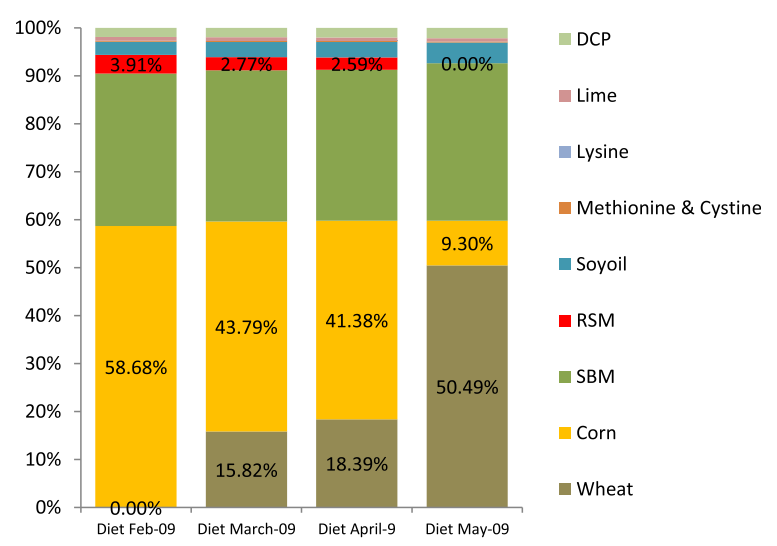

Fig. 7 Illustration of multi stage LP model (CWSR) starter diet formulation results for four consecutive months between Feb and May 2009 at increasing corn wheat price spread above 10 USD/ton, and its impact on RSM and other input substitutions. The price spread (wheat/corn) was estimated at 96\% in Feb-09 and went down to 83\% in May-09

additional energy source (also indicated by the correlation matrix in Additional file 1: Annex 3, of 0.95 between dietary wheat and soy oil). For instance, in the starter diet, and at $50 \%$ wheat inclusion rate, soy oil was included at $4.3 \%$. Meanwhile, at a $60 \%$ corn inclusion rate, soy oil was only $2.2 \%$ of the feed ration. Figure 7 provides an example of simulated starter broiler diets in four consecutive months in 2009 as a response to an increasing price spread between corn and wheat and its impact on the RSM inclusion rate.

Unlike the grains substitution relationship, meal substitution rates showed different patterns and appear to exhibit weak correlations with the price spread of meal inputs. Additional file 1: Annexes 1 and 2 show the ranked price spread between corn and wheat (i.e., wheat price/corn price) and between SBM and RSM. It further shows the inclusion rate corresponding to the ranked price spread. In the simulated starter and grower diets, at a price spread of less than $79 \%$, diets were based on wheat with minimal corn inclusion. At price spreads greater than or equal to $92 \%$, corn remained in the diet at the maximum inclusion rate and substituted for wheat completely. With a price spread between 79 and 92\%, the substitution between corn and wheat was disconnected; however, corn appeared more frequently in the starter diet than in the other diets. The disconnection between corn and wheat at this stage was also influenced by the price of other feed additives. Similar results were obtained from the simulated finisher diet; however, at a price spread of $86 \%$, corn remained in the diet at the maximum inclusion rate and replaced wheat completely. The first position for dietary switch from wheat to corn occurred when the wheat price was $80 \%$ of the corn price. At this price spread, the results show two levels of substitution rate-one in the starter diet where corn substituted $70 \%$ of wheat and the second in the grower and finisher diets where corn substituted $100 \%$ of wheat. Nevertheless, the price spread borders found in our study could diverge slightly depending on the physical objective function prices used.

Three levels of SBM and RSM (RSM/SBM) price spread can be identified. First, in the starter and the grower diets, with a price spread lower than $48 \%$, RSM remained in the formulated diets. Second is the price spread of greater than $70 \%$ in which inclusion of RSM becomes least important and appears very rarely in the 
formulated diets (i.e., only one time). Third, there exists a price spread of boundaries between 48 and 70\%, in which RSM appeared frequently in the formulated diets. The price spread differed slightly in the finisher formulated diets. With a price spread of less than 53\%, RSM remained in all formulated diets. At a price spread range between 53 and 69\%, RSM appeared frequently in the diets. At a price spread greater than $69 \%$, the inclusion of RSM in the diet became less advantageous, and it appeared only one time in the formulated diets.

The upper and lower objective coefficients for feeds used in the CWSR model are shown in Additional file 1: Annex 7. The figure shows clearly that the upper price for wheat is unbounded in most of the studied periods compared to a narrow price range for corn. The composition of the simulated diets is most sensitive to corn price, but that the optimal mix of feeds is ultimately not very stable and highly dependent upon the relative price of feed inputs at any given time.

Additional file 1: Annexes 4 and 5 provide the correlation matrix between the simulated dietary feed components in the grower and finisher diets of the CWSR model. This chart is presented to show the importance of the multi-stage LP modeling process in developing the relationship between dietary components in dietary simulation analyses. The figure clearly indicates that wheat inclusion is correlated with soy oil inclusion rates (corr. $=0.95$ and $R^{2}=0.90$ ). On the other hand, there is a negative correlation between the inclusion of corn and that of soy oil (corr. =0.96 and $R^{2}=0.92$ ). A similar correlation trend was found between these feeds in the grower and finisher diets. This is attributed to the low energy content in wheat versus corn grains, and therefore, additional dietary energy sources were provided by soy oil. Furthermore, the inclusion of wheat was negatively correlated with the inclusion of corn $(-1.00)$, which is expected since in most cases the formulated diets where composed of one of these energy feeds. Furthermore, wheat inclusion

Table 5 Minimum, maximum, mean, and RMSE of ME, protein, and lysine in starter, grower, and finisher formulated broiler diets

\begin{tabular}{|c|c|c|c|c|c|c|c|c|c|}
\hline & \multicolumn{3}{|c|}{ ME (Mcal/kg feed) } & \multicolumn{3}{|c|}{ Protein (\%) } & \multicolumn{3}{|c|}{ Lysine (\%) } \\
\hline & Starter & Grower & Finisher & Starter & Grower & Finisher & Starter & Grower & Finisher \\
\hline \multicolumn{10}{|l|}{ CSD model } \\
\hline Min & 3.05 & 3.1 & 3.15 & 22 & 20 & 18.26 & 1.15 & 1.04 & 0.94 \\
\hline Max & 3.05 & 3.1 & 3.15 & 22.12 & 20.57 & 19.06 & 1.15 & 1.04 & 0.94 \\
\hline Mean & 3.05 & 3.1 & 3.15 & 22.08 & 20.39 & 18.81 & 1.15 & 1.04 & 0.94 \\
\hline STDEV & 0 & 0 & 0 & 0.06 & 0.27 & 0.38 & 0 & 0 & 0 \\
\hline RMSE absolute & 0 & 0 & 0 & 0.1 & 0.48 & 0.89 & 0 & 0 & 0 \\
\hline RMSE \% & 0 & 0 & 0 & 0.45 & 2.33 & 4.74 & 0.17 & 0 & 0.043 \\
\hline \multicolumn{10}{|l|}{ CWSR model } \\
\hline Min & 3.05 & 3.1 & 3.15 & 22 & 20 & 18.05 & 1.15 & 1.04 & 0.94 \\
\hline Max & 3.05 & 3.1 & 3.15 & 22.65 & 21.26 & 19.75 & 1.18 & 1.05 & 0.94 \\
\hline Mean & 3.05 & 3.1 & 3.15 & 22.09 & 20.19 & 18.43 & 1.17 & 1.04 & 0.94 \\
\hline STDEV & 0 & 0 & 0 & 0.23 & 0.45 & 0.58 & 0.01 & 0 & 0 \\
\hline RMSE & 0 & 0 & 0 & 0.25 & 0.48 & 0.72 & 0.02 & 0 & 0 \\
\hline RMSE \% & 0 & 0 & 0 & 1.11 & 2.23 & 3.91 & 1.77 & 0.15 & 0 \\
\hline
\end{tabular}


had a negative correlation with RSM of -0.53 and a positive correlation found with Meth. Cyst. (0.88 in the starter diet and 0.75 in the grower diet) and a low correlation of 0.37 found in the finisher diet. These results indicate that in wheatbased diets, additional synthetic Meth. Cyst. is needed to meet the requirements when RSM is not used in the formulation. A similar conclusion can be drawn when testing the correlation between SBM and methionine. However, the negative correlation between RSM and Meth. Cyst. indicates that this byproduct is an interesting source to reduce expensive synthetic amino acids in diets. Simulated compound feed prices are presented in Additional file 1: Annex 8. These prices will differ by location as they do not represent the farm gate feed price due to the omission of transportation and retailer costs, which are regionally dependent. Compared to a static and standard ration (corn and SBM based diet), using a multistage LP model, it is possible to generate a feed ration which, when looking at the year 2014, could give an average cost reduction of 8.8 USD per ton of starter feed, 4.6 USD per ton of grower feed, and 1.3 USD per ton of finisher feed (CSD model). This results in an average price reduction of 5.9 USD per ton of formulated feed. If we apply this price reduction for the year 2014, it results in a total cost reduction of 1.74 billion USD for starter, grower, and finisher feed combined, meaning that the broiler sector would have gained over 1.74 billion USD in 2014 benifiting from a monthly feed formulation and from inclusion of byproducts. Assuming a similar price reduction in layer chicken feed production, the magnitude of global poultry industry gain will increase up to 2.57 billion USD. The gain could be more than double if other livestock species are included in the analysis, given that the byproducts inclusion rate is of greater importance for ruminants. Using local byproducts may result in lower production costs and reduced greenhouse gas emissions, mainly associated with reduced transportation distances for feed inputs (Hristov et al. 2013).

In a broader sense, optimization of a life cycle animal diet, in a multi-stage approach, would most likely affect other parts of the supply chain. This could include commodity transportation between producing and importing countries, since feed demand would vary widely.

\section{Model evaluation}

Table 5 provides information about the optimization errors of ME, protein, and lysine. The model evaluation is based on the calculated root mean squared error (RMSE), given in absolute value and percentage of ration. In relation to the multiple formulation data obtained from successfully solved LPs, the error level caused by the proposed model was calculated. The major optimization errors are caused by the deviation of crude protein results from the nutritional requirement constraints. It is observed that the error level increases with reducing $\mathrm{CP}$ requirements from the starter to finisher diets, with RMSE ranging between 0.1 and 0.89 in the CSD model versus lower error level observed in the CWSR model which ranged between 0.1 and 0.70 . This could be partially explained by the higher number of feed ingredients used in the CWSR model (i.e., two energy sources and two protein sources). With more feed items included in the formulation, the complementary nature of nutrients in different ingredients promotes the reduction of nutrient 
variation as reported by Zhang and Roush (2002). However, in our study, the CP and lysine standard deviations were lower than, or similar to, those found in their study with a single cost minimization objective. Furthermore, minimizing $\mathrm{CP}$ and amino acid nutrients requires a multiple objective optimization, which is not the objective of the current study. Most likely, additional feeds need to be included in the formulation to minimize errors; however, this depends on the availability of historical feed and byproduct prices.

\section{Conclusions}

Time series diet formulation can provide insights for both feed commodity traders and feed producers to formulate cheaper diets, which would still meet the nutrient requirements for animals. Additionally, time series diet formulations provide the option to periodically include inexpensive agro-industrial byproducts, which are often sourced locally. Furthermore, when future commodity prices are known, the application of the model can be of particular importance for medium- and long-term feed producers' resources planning and estimation of the future sustainable dietary composition. It is important, however, to also consider the diversity of feed resources that are available in a region and to consider the variation between feed prices in order to extract representative results. In particular cases, since not all companies own least cost formulation analysis tools, the model outputs obtained from our analysis could be further utilized to extrapolate major feed inclusion rates (however, not the feed additives) based on market feed prices without referring to LP models (i.e., modeling price impact on DDGS dietary inclusion rate).

This study addressed the nutritional and economic benefits of using a multi-stage LP optimization model in broiler feed formulation. The model provides information to feed producers and traders to determine potential switch points between commodities based on the price spread level. There are two primary limitations of the approach presented in this paper. First, the constraints are linear, thereby forcing corner solutions and discrete jumps between feed inputs. This may, however, be a realistic interpretation of the behavior of firms when considering contracting and transportation costs. Second, this model only examines the cost of inputs in feed mix and dietary requirements, while profit-maximizing behavior likely includes additional objectives and constraints. However, by examining the dietary feed commodity switch between months, we demonstrate variations in feeding strategies and opportunities to minimize feed cost-of primary significance in the livestock production profit function-over a given time period. Our model is built on an open source environment and can be broadly implemented by decision-makers to explore and test further modeling scenarios which suit the production objectives. Furthermore, if feed price forecasts are available, the model can also be automated to predict the least cost dietary dynamics and price spread.

\section{Additional file}

Additional file 1: Annex 1: Corn and wheat inclusion rates in broiler diets as a function of corn-wheat price spread in the CSD model. a Starter. b Grower. c Finishers. Annex 2: SBM and RSM inclusion rates in broiler diets as a function of SBM-RSM price spread in the CWSR model. a Starter. b Grower. c Finishers. Annex 3: Correlation matrix of optimized feed composition in the simulated starter diet of the CWSR model. Annex 4: Correlation matrix of optimized feed composition in the simulated grower diet of the CWSR model. Annex 5: Correlation matrix of optimized feed composition in the simulated finisher diet of the CWSR model. Annex 6: Upper and lower simulated price boundaries of feeds in the CSD LP model between 2008 and 2016. Annex 7: Upper and lower simulated price 
boundaries of feeds in the CWSR LP model between 2004 and 2015. Annex 8: Simulated compound feed price for starter, grower, and finisher broiler diets in the CWSR and CSD models. (DOCX $2340 \mathrm{~kb}$ )

\section{Authors' contributions}

OA developed the model, collected data, analyzed the results and graphics, and drafted the earlier manuscript versions. AN provided inputs on the literature review, extracted the results, and contributed to discussions. RBW edited the drafted manuscript and provided inputs to the discussions. All authors have read and approved the final manuscript.

\section{Competing interests}

The authors declare that they have no competing interests.

\section{Publisher's Note}

Springer Nature remains neutral with regard to jurisdictional claims in published maps and institutional affiliations.

\section{Author details}

'Department of Animal and Veterinary Sciencs, College of Agricultural and Marine Sciences, Sultan Qaboos University, P.O. Box 34, 123 Al khoudh, Sultanate of Oman. ${ }^{2}$ Wageningen Livestock Research, Wageningen University and Research, P.O. Box 338, 6700 AB Wageningen, The Netherlands. ${ }^{3}$ Department of Agricultural and Applied Economics, Texas Tech University, Lubbock, TX 79409; Texas AgriLife Research -Lubbock, Lubbock, TX 79403, USA.

Received: 18 April 2017 Accepted: 20 November 2017

Published online: 22 December 2017

\section{References}

Alltech. (2016). Presentation on: Global feed tonnage, available under the link: https://cdn2.hubspot.net/hubfs/745395/ PDFs/2016_Global_Feed_Survey_FINAL_Slides.pdf, visited on Nov. 2016

Alqaisi O, Hemme T, Latacz-Lohmann U, Susenbeth A (2014) Evaluation of food industry by-products as feed in semi-arid dairy farming systems: the case of Jordan. Sust Sci J 9:361-377

Alqaisi O, Ndambi OA, Hemme T (2011) Global view on feed cost and feed efficiency on dairy farms. All About Feed magazine. $2 \mathrm{nr} .4$

Beckman J, Keeney R, Tyner W (2011) Feed demands and coproduct substitution in the biofuel era. Agribusiness 27:1-18. https://doi.org/10.1002/agr.20247

de Visser, CLM, Schreuder R, Stoddar R (2014) The EU's dependency on soya bean import for the animal feed industry and potential for EU produced alternatives OCL-OI Corps Gras Li 21 p. D407

Donohue M, Cunningham DL (2009) Effects of grain and oilseed prices on the costs of US poultry production. J App Poult Res 18(2):325-337

FAO, IFPRI (International Food Policy Research Institute), IFAD, IMF (International Monetary Fund), OECD (Organization of Economic Cooperation and Development), UNCTAD (United Nations Conference on Trade and Development), World Bank, World Food Programme, WTO (World Trade Organization), and the United Nations High-Level Task Force (2011) Price volatility in food and agricultural markets: policy responses, policy report

Godfray HCJ, Beddington JR, Crute IR, Haddad L, Lawrence D, Muir JF, Pretty J, Robinson S, Thomas SM, Toulmin C (2010) Food security: the challenge of feeding 9 billion people. Science 327:812-818

Gopinger E, Xavier EG, Elias MC, Catalan AAS, Castro MLS, Nunes AP, Roll VFB (2014) The effect of different dietary levels of canola meal on growth performance, nutrient digestibility, and gut morphology of broiler chickens. J Appl Poult Res 93:1130-1136

Hoffmann LA, Baker A (2011) Estimating the substitution of distillers' grains for corn and soy bean meal in the U.S. feed complex/FDS-11-I-01, Washington D.C. Economic Research Service/USDA. https://www.ers.usda.gov/webdocs/ publications/36471/12563_fds11i01_2_.pdf?v=42426

Hristov AN, Oh J, Lee C, Meinen R, Montes F, Ott T, Firkins J, Rotz A, Dell C, Adesogan A, Yang W, Tricarico J, Kebreab E, Waghorn G, Dijkstra J, Oosting S (2013) Mitigation of greenhouse gas emissions. In Gerber, PJ, Henderson, B and Makkar, HPS. Eds. Livestock production - a review of technical options for non-CO2 emissions. FAO animal production and health paper no. 177. FAO, Rome, Italy

Leeson S, Summers JD (2005) Commercial poultry nutrition, 3rd edn. Nottingham University Press, Nottingham

Loar RE, Donaldson JR, Corzo A (2012) Effects of feeding distillers dried grains with solubles to broilers from 0 to 42 days posthatch on broiler performance, carcass characteristics, and selected intestinal characteristics. J Appl Poult Res 21:48-62

Makkar HPS, Ankers P (2014) Towards sustainable animal diets: a survey-based study. Anim Feed Sci Technol 198:309-322

Nicholson CF, Lee DR, Boisvert R, Blake RW, Urbina CI (1994) An optimization model of dual purpose cattle production in the humid lowlands of Venezuela. Agric Syst 46:311-334

NRC (1994) Nutrient requirements of poultry. Ninth revised edition, 1994. National Academy Press, Washington D.C

Peric T, Babic Z (2009) Optimization of industrial production of feed blends as multiple criteria programming problem, recent advances in technologies. Maurizio AS (Ed.), Available from: https://cdn.intechopen.com/pdfs-wm/9278.pdf

Pesti, G.M., Miller, B.R. 1993. Animal feed formulation, economics and computer applications. AVI book, van nonstrand Reinhold. Georgia, USA

R Core Team (2016) R: a language and environment for statistical computing. R Foundation for Statistical Computing, Vienna URL https://www.R-project.org/. 
Reynoso-Campos O, Fox DG, Blake RW, Barry MC, Tedeschi LO, Nicholson CF, Kaiser HM, Oltenacu PA (2004)

Predicting nutritional requirements and lactation performance of dual-purpose cows using a dynamic model. Agric Syst 80:67-83

Saxena P, Chandra M (2011) Animal diet formulation: a review (1950-2010). Anim Sci Rev 6(57):1-9 (CAB Reviews: Perspectives in Agriculture, Veterinary Science, Nutrition and Natural Resources, UK)

Saxena P (2011) Comparison of linear and nonlinear programming techniques for animal diet. Appl Math 1:106-108. https://doi.org/10.5923/j.am.20110102.17

Singh D, Saxena P (2015) Optimization of livestock feed by blend of linear programming and SOMGA. In: Das KN et al (eds) Proceedings of fourth international conference on soft computing for problem solving, advances in intelligent systems and computing, vol 336. https://doi.org/10.1007/978-81-322-2220-0_27

Thacker PA, Petri D (2011) Nutritional evaluation of canola protein concentrate for broiler chickens. Asian-Australas J of Anim Sci 24:1607-1614

USDA (2016). Biofuel feedstock and coproduct market Data. http://www.ers.usda.gov/topics/farm-economy/bioenergy/ biofuel-feedstock-coproduct-market-data/. visited on Oct. 2016.

Walugembe M, Rothschild MF, Persia ME (2014) Effects of high fiber ingredients on the performance, metabolizable energy and fiber digestibility of broiler and layer chicks. Anim Feed Sci Technol 188:46-52

World bank (2016) monthly commodity feed prices. http://www.worldbank.org/en/research/commodity-markets. visited on Dec. 2016.

Žgajnar J, Erjavec E, Kavčič S (2010) Multi-step beef ration optimisation: application of linear and weighted goal programming with a penalty function. Agri and Food Sci 19:193-206

Zhang Z, Roush WB (2002) Multiple-objective (goal) programming model for feed formulation: an example for reducing nutrient variation. Poultr Sci 81:182-192

Submit your manuscript to a SpringerOpen ${ }^{\circ}$ journal and benefit from:

- Convenient online submission

- Rigorous peer review

- Open access: articles freely available online

- High visibility within the field

Retaining the copyright to your article

Submit your next manuscript at $\gg$ springeropen.com 